Revista Digital Universitaria

Vol. 22, Núm. 6, noviembre-diciembre 2021

\title{
De la Política Internacional al Proyecto Emergente de Enseñanza Remota de la Universidad Autónoma Metropolitana
}

\author{
Miguel Ángel Gallegos Cárdenas
}

\begin{abstract}
Resumen
A partir del contexto de aislamiento físico que implicó la pandemia ocasionada por el virus SARS-CoV-2, el cual genera la enfermedad denominada covid-19, los sistemas educativos se vieron en la necesidad de hacer ajustes a sus procesos de enseñanza-aprendizaje. Bajo este escenario, este trabajo revisa la manera en la que el marco normativo internacional brindó las directrices y acciones a implementar a los gobiernos en todo el mundo, para que se tomarán decisiones que permitieran afrontar de la mejor manera posible los impactos socioeconómicos generados por la emergencia sanitaria. En particular, se describe cómo un discurso oficial de Organización de las Naciones Unidas (onu) dio pauta para hacer uso de diversos dispositivos, recursos y plataformas digitales que permitieran seguir brindando los servicios ofertados en los diferentes niveles y modalidades educativas, y cómo a partir de él se conformó el Proyecto Emergente de Enseñanza Remota (PEER) de la Universidad Autónoma Metropolitana (UAm).
\end{abstract}

Palabras clave: onu, covid-19, Política Educativa Internacional, Tecnología educacional, uAm.

\section{From International Policy to the Emerging Remote Teaching Project of the Autonomous Metropolitan University}

\begin{abstract}
From the context of physical isolation brought about by the global pandemic by the virus SARS-CoV-2, which causes the disease covid-19, educational systems needed to adjust their teaching-learning process. Under this scenario, this paper reviews the international regulatory framework that provided the guidelines and actions to be implemented by governments around the world to make decisions to address socioeconomic impacts generated by the health emergency. Particularly, we describe how an official discourse by the United Nations (UN) dictated the guidelines to make use of various devices, resources and digital platforms that would allow to continue providing the services offered at different levels and educational modalities, and how, from this official discourse, the Emerging Project for Remote Education (PEER) at the Autonomous Metropolitan University (UAM) was formed, what it consists on and how it is related to policies suggested by the un.
\end{abstract}

Keywords: UN, covID-19, International Educational Policy, Educational Technology, UAM. 
Licenciado en Administración, maestro en Desarrollo y Planeación de la Educación, egresado del doctorado en Ciencias Sociales, área de investigación Sociedad y Educación, en la Universidad Autónoma Metropolitana (AUM), Unidad Xochimilco. Docente y orientador educativo digital en la Secretaría de Educación Pública (SEP).

\section{Introducción}

E I fenómeno de cambio socioeconómico, en los diversos sectores de todo el mundo, tiene su origen a fines del año 2019, en la pandemia generada por el virus SARS-CoV-2, el cual produce la enfermedad denominada covid-19. En ese sentido, el objetivo de este trabajo es el de describir cómo se conformó el discurso oficial que dictaría la guía para que los gobiernos y las instituciones educativas a nivel internacional, auxiliadas de las tecnologías digitales, contuvieran y afrontaran de la mejor manera la continuidad para brindar el servicio educativo. Para ello, se confronta el discurso oficial con la implementación de una estrategia en una universidad, explorando y analizando cómo se conformó, en qué consiste y cómo se relaciona el Proyecto Emergente de Enseñanza Remota (PEeR) de la Universidad Autónoma Metropolitana (UAM) con las políticas sugeridas por la Organización de las Naciones Unidas (ONu).

El distanciamiento físico presencial obligó a los aparatos educativos a cambiar sus formas de operación y funcionamiento tradicional. A partir de ello, se generó una problemática a la que se enfrentaron las instituciones educativas en todos los niveles escolares. Ésta radica en que los recintos escolares fueron cerrados, lo que imposibilitó el trabajo presencial al que se estaba acostumbrado $y$, sobre todo, a las formas de trabajo de manera física y presencial, pues las mismas secuencias de actividades, relaciones interactivas, organización social, espacio y tiempo dedicados, contenidos, materiales utilizados, criterios y formas de evaluación, daban como resultado ciertas prácticas educativas tradicionales (Zabala, 2000). Pero el insólito escenario trajo la necesidad de considerar otras alternativas para llevar a cabo nuevas prácticas educativas, acordes al contexto de distanciamiento físico y presencial. 
Al respecto, cabe mencionar que, en uno de sus discursos oficiales, el secretario general de la onu, António Guterres, señaló lo que muchos gobiernos y funcionarios públicos volverían su discurso oficial: "No podemos sencillamente volver al mismo punto en el que nos encontrábamos antes del impacto del coviD-19, con sociedades innecesariamente vulnerables a las crisis. Tenemos que construir un mundo mejor" (onu, 2020, p. 44). Con el crecimiento de la pandemia, el discurso oficial empezaba a gestarse y difundirse cada vez con más fuerza, ya que el Marco de la onu señala que no se volverá a la "antigua normalidad" (onu, 2020, p. 46).

Ante esta directriz del máximo organismo y de sus diversas oficinas en todo el mundo, se comenzó a replicar dicho discurso, tal como también lo señaló el sitio electrónico de la onu México (2020). Coincidentemente, el Programa de las Naciones Unidas para el Desarrollo (PNUD) publicó el comunicado: Una nueva normalidad (2020), con las directrices de establecer una ruta para rescatar las economías y salvaguardar los empleos. El término nueva normalidad tiene su origen en estos organismos internacionales.

Al mismo tiempo, el presidente de México, Andrés Manuel López Obrador, anunciaría la conformación del Plan de regreso a la Nueva Normalidad (Noticieros televisa, 2020). Lo mismo hacían diversas instituciones y dependencias nacionales como la Secretaría de Economía de México (cNN, 2020), y el gobierno de la capital, que presentaría el Plan Gradual hacia la Nueva Normalidad en la Ciudad de México (Gobierno cDmx, 2020). Desde lo internacional y lo nacional, se dictaban las directrices para construir la nueva normalidad social y educativa.

\section{Directrices de la nueva normalidad en la educación oficial}

Ante la pandemia y con las directrices de la nueva normalidad, el cierre de las escuelas fue inevitable. En todos los niveles y modalidades escolares se tuvieron que implementar medidas y acciones para, pese a todo, sacar adelante los calendarios educativos.

En el informe Responsabilidad compartida, solidaridad mundial, se proporcionan las directrices para utilizar las Tecnologías de la Información y la Comunicación (TıC). En él se señala: "Las tecnologías digitales se han convertido en un elemento de apoyo positivo en esta crisis, facilitando la continuidad de las operaciones, conectando a las personas más que nunca y ayudándolas a mantener una buena salud mental" (onu, 2020, p.13). El acceso a la información, sobre todo a la digital, comenzaría a jugar un papel relevante en los procesos y ámbitos educativos.

Al mismo tiempo que se solicitaba apoyar a los docentes, progenitores y cuidadores para favorecer la adaptación a las modalidades de enseñanza en el hogar (onu, 2020, p. 23, 2020), se señalaba que, para preservar la calidad de la educación para los niños y los jóvenes, se deberían implementar diversas acciones como la educación a distancia, acceso a préstamos o a transferencias 
de equipo para los alumnos o los hogares, prestación de conexión a internet, alianzas público-privadas para que las plataformas y las herramientas para la educación a distancia estuvieran a disposición de manera gratuita, recursos digitales de aprendizaje para docentes y progenitores, así como aplicaciones educativas electrónicas multilingües gratuitas, para facilitar el aprendizaje durante los períodos de cierre de las escuelas (onu, 2020, p. 24).

Por otro lado, el Marco de la onu para la respuesta socioeconómica inmediata ante el brote de covid-19, en el apartado del Sistema de Naciones Unidas para el desarrollo en el área educativa, señalaba que se trabajaría con las autoridades educativas nacionales y con los proveedores de servicios educativos del sector privado para respaldar a las instituciones de educación preescolar y a las escuelas que puedan permanecer abiertas de forma segura. También establecía que asistiría a los gobiernos para extender el uso de herramientas digitales y otras formas de aprendizaje remoto (onu, 2020).

Un sector que se puede abordar para conocer cómo actuaron las instituciones educativas es el de la educación superior, dado que las universidades han tenido que reconvertirse en virtuales de la noche a la mañana (Orihuela, 2020). En este contexto, la Secretaría de Educación Pública (SEP) instruyó a la Subsecretaría de Educación Superior (SES), y generó los Lineamientos de acción coviD-19, para que se implementarán las acciones correspondientes acorde a cada modelo universitario.

\section{Proyecto Emergente de Enseñanza Remota (PEER) de la UAM-X}

El anunciado cierre de las instalaciones universitarias se daba cuando los organismos internacionales dictabany promovían las directrices para implementar estrategias con el uso de tecnologías digitales, para poner en marcha proyectos emergentes de educación remota. Para contrastar cómo se implementaron las recomendaciones señaladas por la onu, se analiza la estrategia de la Universidad Autónoma Metropolitana (UAM), la cual puso en marcha el Proyecto Emergente de Enseñanza Remota (PEER) de la UAM, aprobado en su sesión urgente (474) de su colegio académico. Su objetivo fue dar continuidad a la actividad universitaria, brindando seguridad a toda la comunidad de esta casa de estudios.

Para poner en marcha dicha estrategia, se planteó apegarse a cuatro ejes rectores:

1. Ser contingente. Dar coontinuidad de las funciones sustantivas de la universidad para hacer frente a un hecho y momento únicos. Se cierran las instalaciones, pero se abre la universidad a la virtualidad.

2. Multitecnología. Integrar una diversidad de herramientas tecnológicas para que los agentes educativos puedan comunicarse e interactuar, considerando varias opciones, en el entendido de los diferentes perfiles de docentes y estudiantes. Se brinda cierta facultad de libertad de elegir, de acuerdo a cada actor educativo y particularmente de 
los docentes, que son quienes guían el proceso educativo. Asesorar, acompañar y asistir tanto a estudiantes como a docentes, habilitar el micrositio UAM VIRTU@L en que se ofrecen plataformas, recursos y alternativas de apoyo durante la emergencia.

3. Flexible. Comprensible y accesible para poder llevar a cabo la actividad docente, utilizando las tecnologías para la enseñanza, evaluación y presentación de informes de investigación. Es fraterno para fortalecer el diálogo y la intercomunicación para atender problemáticas que se presenten. Dar libertad para la construcción de espacios para enseñanza, evaluación y seguimiento en la enseñanza remota. Se brinda la confianza a los actores educativos.

4. Incluyente. Se da apoyo para la conectividad y acceso a la enseñanza remota. Es decir, se acepta que no hay igualdad de circunstancias en la accesibilidad a las diversas tecnologías y recursos digitales. Para equilibrar los diferentes escenarios que algunos agentes requieren, la UAm brinda apoyo de beca en especie, tanto en dispositivos tecnológicos como en conectividad, reduciendo con ello la brecha digital entre la comunidad universitaria.

Con las directrices generales señaladas en el proyecto PEER, los más de 45,000 alumnos y los cerca de 3,000 académicos, distribuidos en las cinco unidades académicas -Azcapotzalco, Cuajimalpa, Iztapalapa, Lerma y Xochimilco-, dieron continuidad a las actividades y recomendaciones de los organismos internacionales, para poner en marcha el trimestre lectivo 20/ı (que abarcó del 11 de mayo al 17 de julio 2020, con una duración, por única ocasión, de nueve semanas). Se trató de un trimestre atípico en esta universidad, pues fue el primero en implementar la estrategia remota.

Es así como este proyecto se puso en marcha, apegándose a las recomendaciones de los organismos internacionales. Incluso el título que se le otorgó a la estrategia fue el de enseñanza remota, término sugerido en los documentos rectores de la onu, pero que, al mismo tiempo, es un concepto surgido durante la crisis pandémica. De este modo, en términos prácticos, la emergencia remota se refiere a trasladar hacia un medio virtual el proceso de enseñanza-aprendizaje, originalmente pensado para una modalidad presencial (Cabrales, 2020).

Con esta referencia, se comprende que la estrategia implementada por la uam fue la más acertada, dado que en su modelo educativo ha prevalecido la modalidad presencial, por lo que no se contaba del todo con la infraestructura, recursos y experiencia para el trabajo a la distancia. Es por ello que en otro momento se reflexionará sobre las prácticas educativas, los dispositivos, recursos y plataformas digitales utilizadas por los académicos y estudiantes durante el peER de la UAM. 
Para finalizar, cabe formular las preguntas: ¿qué sucedió en los diferentes niveles y modalidades educativas? y ¿cuáles fueron las estrategias, acciones y medidas implementadas, en el entendido que cada aparato universitario tiene sus propias características y particularidades? Será conveniente investigar qué sucedió en otros proyectos de educación superior en México.

\section{Referencias}

* Alís, K. (2020, 18 de mayo). Gobierno de México anuncia lineamientos para el ingreso a la nueva normalidad. cNn. https://cnn.it/3kixuHD

* Cabrales, A., Graham, A., Sahlberg, P., Hodges, C., Moore, S., Lockee, B., Trust, T., Bond, A., Lederman, D., Greene, J., Maggioncalda, J., Soares, L., Veletsianos, G. y Zimmerman, J. (2020, abril). Enseñanza remota de emergencia. Textos para la discusión. The Learning Factor. https://cutt.ly/rEPyhCx

* Castells, M. (2000). La sociedad red. La era de la información: economía, sociedad y cultura: el poder de la identidad. Siglo xxı.

* Gobierno de la Ciudad de México. (2020). Decarga todos los documento del Plan Gradual hacia la Nueva Normalidad en la Ciudad de México. https://covid19.cdmx. gob.mx/nuevanormalidad

* Educación sep. (s.f.). Lineamientos de acción covid-19. Instituciones Públicas de Educación Superior. http://www.anuies.mx/recursos/pdf/LINEAMIENTOS_COVID-19_IES_SES_VFINAL.pdf

* Noticieros Televisa. (2020, 12 de mayo). amlo alista plan para regreso a la 'nueva normalidad' - Las Noticias [video]. YouTube. https://youtu.be/zcONanCRJYI

* onu México. (2020, abril). Una nueva normalidad - onv establece una hoja de ruta para levantar las economías y salvar los empleos después de covid-19. https://bit. ly/3mfvG3R

* Organización de las Naciones Unidas (onu). (2020). Marco de la onu para la respuesta socioeconómica inmediata ante el brote de covID-19. https://bit.ly/2ZzpKc7

* Orihuela, J. L. (2020, 10 de abril). Repensar la universidad en cuarentena. https://bit. ly/33p53k9

* Programa de las Naciones Unidas para el Desarrollo. (2020, 27 de abril). Una nueva normalidad. https://bit.ly/2ZzKH6G

* UAMVIDEOS. (2020, 17 de abril). Sesión Número 474 (urgente) del Colegio Académico [video]. YouTube. https://youtu.be/DwM9woT3J30

* United Nations (UN). (2020a, marzo). Shared responsibility, global solidarity: Responding to the socio-economic impacts of covID-19. https://bit.ly/3itQ2nu

* Universidad Autónoma Metropolitana (s/f). Proyecto Emergente de Educación Remota. https://www.uam.mx/educacionvirtual/uv/peer.html

* Universidad Autónoma Metropolitana (s/f). uAm virtu@l. Espacio de convergencia. https://www.uam.mx/educacionvirtual/uv/index.html 
"De la Política Internacional al Proyecto Emergente de Enseñanza Remota de la Universidad Autónoma Metropolitana" Miguel Ángel Gallegos Cárdenas Vol. 22, Núm. 6, noviembre-diciembre 2021 Revista Digital Universitaria

Universidad Autónoma Metropolitana (Uam). (2020). Anuario estadístico 2020. uAm.

* Universidad Autónoma Metropolitana (UAM). (2020). Seguimiento y evaluación del proyecto emergente de enseñanza remota (PEER) en el trimestre 2021. UAM.

* Zabala, A. (2000). La práctica educativa. Cómo enseñar. Editorial Graó.

\section{Cómo CITAR ESTE ARTículo}

* Gallegos Cárdenas, Miguel Ángel. (2021, noviembre-diciembre). De la política internacional al Proyecto Emergente de Enseñanza Remota de la Universidad Autónoma Metropolitana. Revista Digital Universitaria (RDU), 22(6). http://doi. org/10.22201/cuaieed.16076079e.2021.22.6.9 